\title{
Stability Analysis of a Composite Girder Cable-stayed Bridge
}

\author{
Wusheng Tian ${ }^{1, a}$, Bin Liang ${ }^{1, b}$, Liang Lv ${ }^{2, c}$ \\ ${ }^{1}$ Civil Engineering School, Henan University of Science and Technology, Luoyang 471023, China \\ ${ }^{2}$ Civil Engineering School, Southwest Jiaotong University, Chendu 610000, China

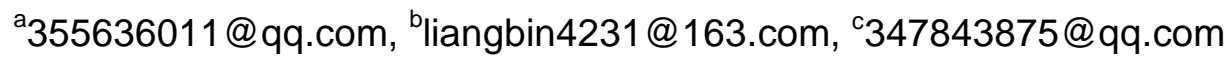

Keywords: ANSYS; cable-stayed bridge; finite element; stability;

Abstract. The Gangjiang No.2 Bridge is studied as the research object. In this paper, a finite element model is established by using ANSYS finite element analysis software in the engineering background of the cable-stayed bridge with double cable plane steel. The results show that it can get the result of the second stablization analysis in different conditions, explaining the stability of the bridge. The stable data obtained in accordance with the relevant specifications, which can provide reference for the construction of similar cable stayed bridge in the future.

\section{Introduction}

With the rapid development of traffic infrastructure in our country, the construction level, China has become the construction of cable-stayed bridge in most countries, the cable-stayed bridge structure forms a variety of steel cable-stayed bridge, concrete cable-stayed bridge, composite girder cable-stayed bridge and hybrid girder cable-stayed bridge. At home, most of the construction of concrete cable-stayed bridge and composite beam cable-stayed bridge. In the past more than and 20 years, by the thin cable system into missile system of cable-stayed bridge, prominent change is the girder section height is smaller, so the quality and flexural stiffness was significantly reduced.

The Gangjiang No. 2 Bridge as the research object, using the finite element software ANSYS15.0 to establish the finite element model of the cable-stayed bridge is analyzed two kinds of stable, more realistic simulation of the bridge state, analysis of the relationship between the changes of load and displacement, obtain reliable data, provide the technical reference for design and construction this type of bridge in future, to help make better optimization of the bridge.

\section{Project Profile}

Gangjiang No.2 Bridge with $2529 \mathrm{~m}$ span is a cable\& stayed bridge with twin towers, twin cable planes and semi-floating superposed beams. The bridge span is $54+114+400+114+54 \mathrm{~m}$. The general arrangement is shown in Figure 1. The standard section of the main beam is shown in Figure 2. Double tower is a reinforced concrete structure, height of $124 \mathrm{~m}$ above the deck tower height of $100 \mathrm{~m}$, the main tower of effective height and span ratio of 0.25 , the four corners of rectangular section is circular, the tower cross bridge to the curve line.

\section{Finite Element Model}

Using the finite element analysis software ANSYS, the finite element simulation of cable-stayed bridge with Twin Towers Gangjiang No.2 Bridge with double cable planes, $\mathrm{Z}$ axis is along the bridge direction, $\mathrm{X}$ axis is transverse direction, $\mathrm{Y}$ axis is the vertical direction of the bridge. The discrete model of single beam girder for fishbone Daigang of "Brokeback" ("fishbone" unit as the stiffness element, "fish ridge" unit reflect the mixed section of the beam stiffness), fishbone ends hanging cable, the cable at the other end of the anchor in the main tower. The beam188 unit does not have a real constant. The link10 element is a three-dimensional tension or compression member, which is set up to simulate the cable only by the pull rod, and the 42 real constants of the link 10 element are defined by the different cable specifications and the dead load cable force. The full bridge finite element model is shown in Figure 1. 

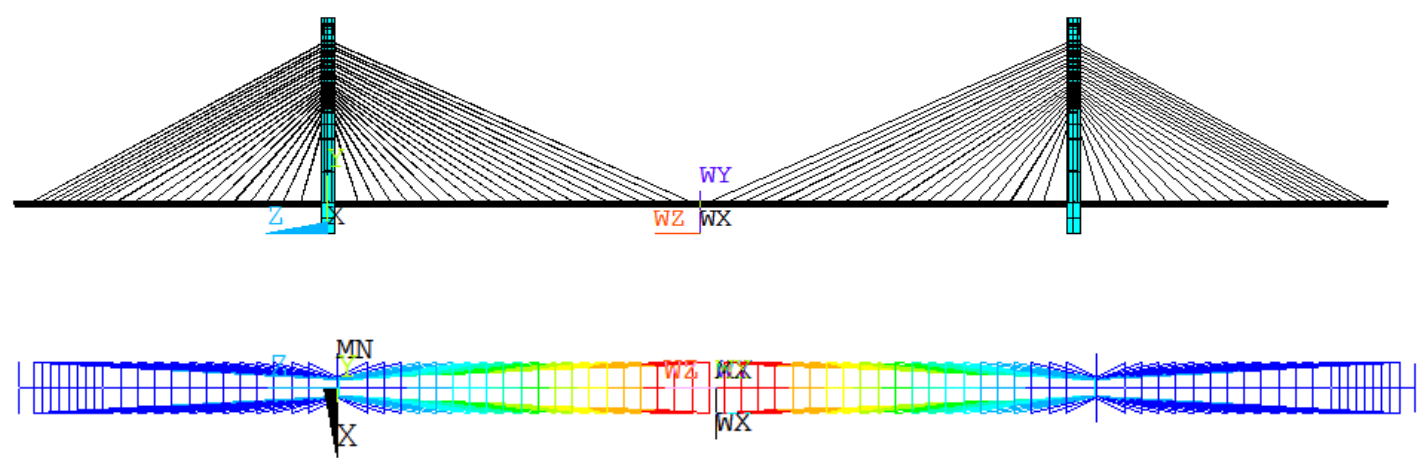

Fig.1 Finite element model of the whole bridge

Nonlinear stability analysis of Gangjiang No.2 Bridge. The main tower is made of C50 concrete and reference concrete structure in China. The constitutive relation of concrete is simplified as a piecewise discounting model, the rising phase of the line by two straight lines, as shown in Figure 4, the main material parameters and corresponding to figure $2: \sigma_{0}=32.4 \mathrm{MPa}, \sigma_{\mathrm{c}}=0.4 \sigma_{0}=12.96 \mathrm{MPa}$, $E_{\mathrm{c}}=34.5 \mathrm{GPa}, \varepsilon_{\mathrm{u}}=0.0033, \varepsilon_{0}=0.002, \varepsilon_{\mathrm{c}}=\sigma_{\mathrm{c}} / E_{\mathrm{c}}=0.00038, E_{0}=\left(\sigma_{0}-\sigma_{\mathrm{c}}\right) /\left(\varepsilon_{0}-\varepsilon_{\mathrm{c}}\right)=12.0 \mathrm{GPa}$ 。

The steel beam is made of $\mathrm{Q} 345 \mathrm{qD}$ steel, the elastic modulus is $210 \mathrm{GPa}$, the yield stress is $345 \mathrm{MPa}$, and the constitutive relation is the ideal elastic-plastic model, as shown in Figure 3.

The cable due to the actual projects of various steel strand strength is not exactly the same, the tension of rope may not be uniformly distributed in the steel strand cable, so the actual breaking stress is slightly lower than the standard tensile strength, namely the actual breaking stress value of efficiency coefficient of standard tensile strength by 0.95 , i.e.. In the calculation, when the stress of a certain stay cable reaches its breaking stress, the cable unit is killed and is no longer a stress component. The technical process is implemented in the ANSYS software through the multi point restart and the birth and death unit functions. As shown in Figure 4.

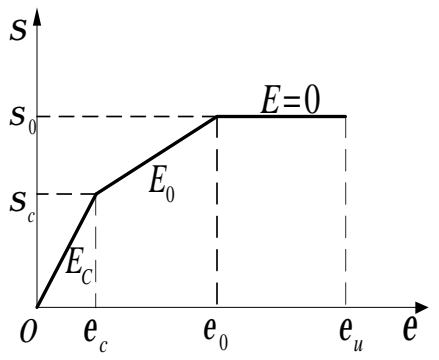

Fig.2 Constitutive relation of $\mathbf{C 5 0}$

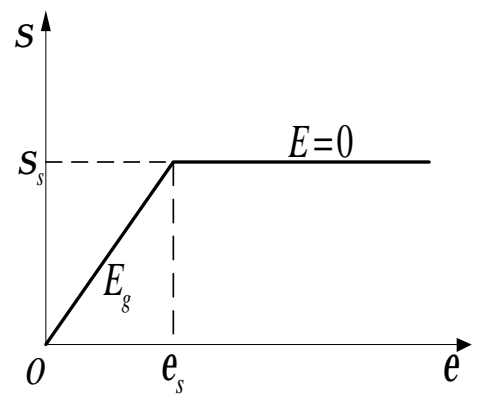

Fig.3 Constitutive relation of Q345qD

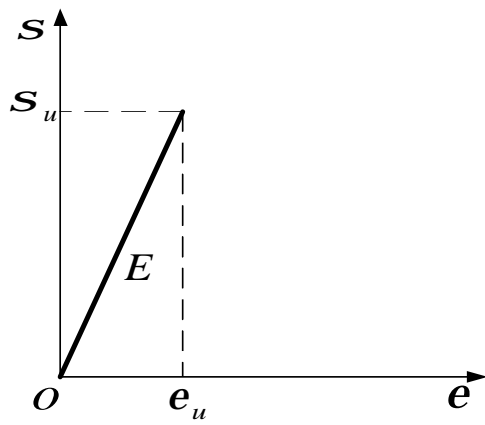

Fig.4 Constitutive relation of Stay cables

For the nonlinear analysis of the bridge, the main consideration of a constant load (bridge), two dead load (the structure of the pavement, railings and other ancillary facilities (load and wind load of the bridge according to the basic wind speed 100 year standard: $23.9 \mathrm{~m} / \mathrm{s}$ ), according to the static equivalent principle applied in equivalent node form load finite element balance equation.

\section{Calculation Results and Analysis}

The analysis and calculation of the nonlinear stability of the deadweight of bridge, two dead load and wind load, safety and stability coefficient of overall structure under the bridge into the Gan River Bridge is $K=2.3$. In order to have a clear understanding of the process of structural change and change, the load factor $\mathrm{K}=1, \mathrm{~K}=2, \mathrm{~K}=2.3$. The overall instability modes of these three stages are shown in Figure 5 to 7. 


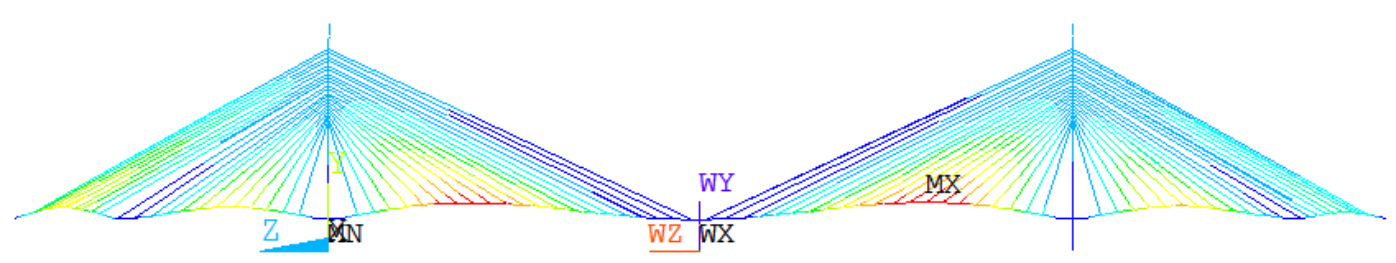

Fig.5 instability mode $\mathrm{K}=1$

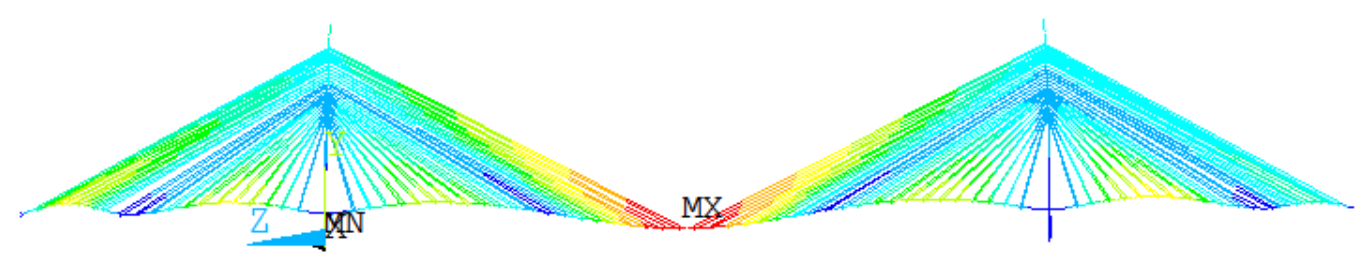

Fig.6 instability mode $\mathrm{K}=2$

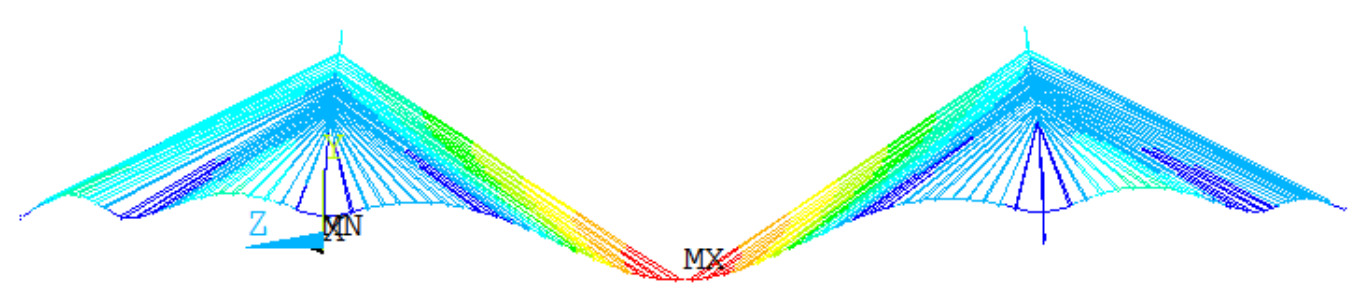

Fig.7 instability mode $\mathrm{K}=\mathbf{2 . 3}$

From Figure $5 \sim 7$ can be seen in the $K=1$, the main tower has shown obvious lateral bending, but due to the vertical loads of bridge cable force of cable and structure at this time is not large, vertical bending performance of girder is not obvious, and because there is no applied Lane load mid span cable force the bridge under the action of even a slight upward. With the increasing loading ratio, the structure of the final buckling mode of main tower in the longitudinal and transverse bending combination girder with vertical and horizontal bending combination, this is due to the reason of the hundred years of the wind load.

It is necessary to study the load displacement curves of the key parts of the structure for the nonlinear stability problem of second kinds of structures. The main span of Gangjiang No.2 bridge design reached the height of tower $400 \mathrm{~m}$, nearly $130 \mathrm{~m}$ in structural mechanics for slender members. As for the main taco approximate cantilever member at the bottom of the consolidation of the tower under load displacement of large, for large span girder, mid span displacement of an object is the need to focus on. Under the load condition, the main tower should pay attention to the longitudinal displacement and transverse position of the top node. The load displacement curves are shown in Figure 8 to 11.

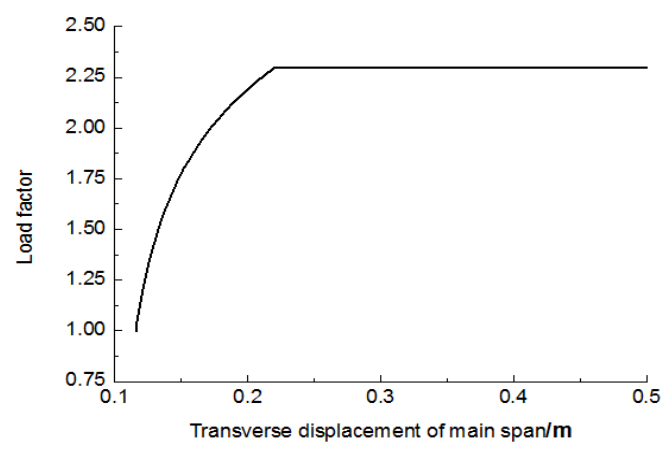

Fig.8 Displacement curve

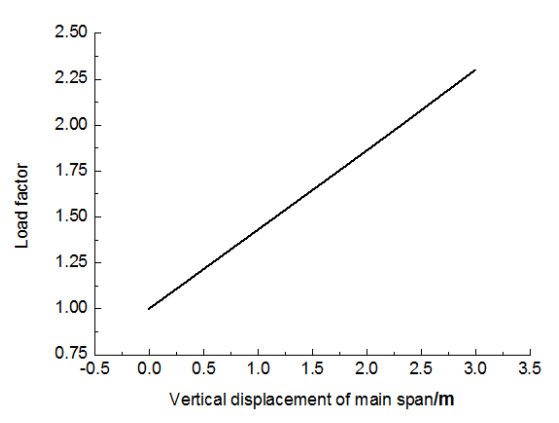

Fig.9 Displacement curve 


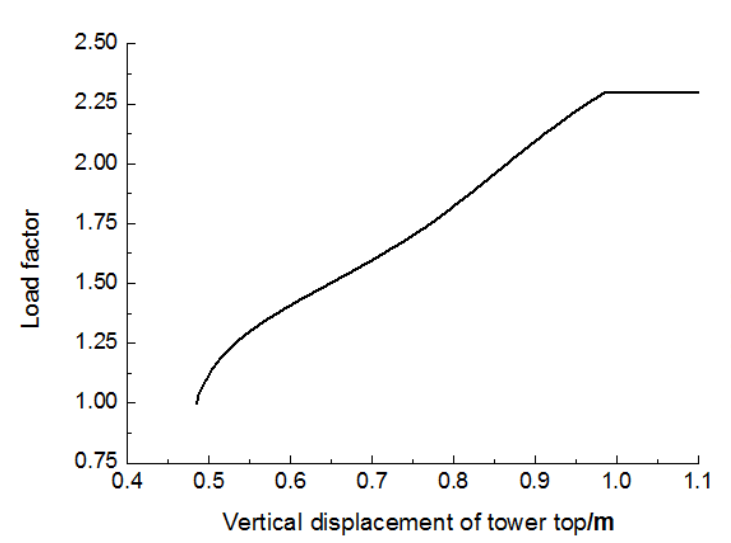

Fig.10 Displacement curve

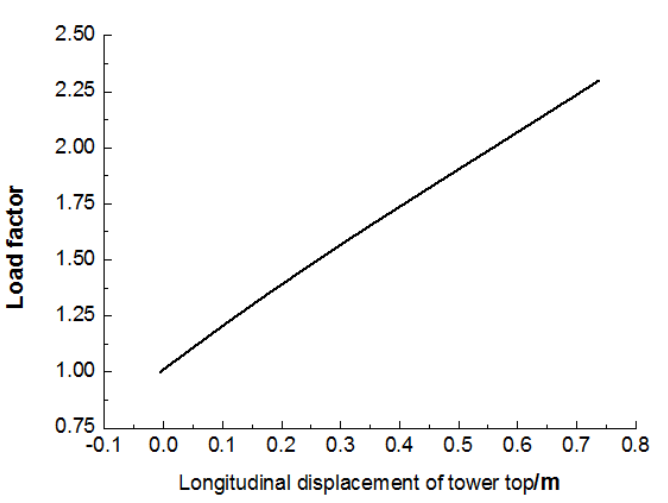

Fig.11 Displacement curve

\section{Conclusion}

In the stability analysis of cable-stayed bridges, the second kind of stability analysis is the key. That is to consider the double nonlinear problem of the junction and the material to achieve the ultimate bearing capacity of the structure. In this paper, the deformation and displacement of the structure are observed by increasing the number of the base load, and finally the damage to the structure is calculated. The safety factor $\mathrm{K}=2.3$ is obtained, which is consistent with the second kinds of stability of cable-stayed bridge.

The overall buckling mode of the structure is combined with the longitudinal and transverse bending of the main tower. And the main girder is connected with the lateral and vertical bending which is due to the loading of the first stage and the two stage of the dead load. The reasons of the wind load are also considered.

Considering the double nonlinear effects of structure and material, the displacement of the structure changes with the load, especially in the transverse direction which shows the obvious nonlinear relationship.

\section{References}

[1] G. L. Dai, B. Yan, Longitudinal forces of continuously welded track on high-speed railway cable-stayed bridge considering impact of adjacent bridge, J. Centsouth University. 19(2012)2348-2353. (In Chinese)

[2] M. H. Zhao, C. Jiang, W. G. Cao, J. H. Liu,Catastrophic model for stability analysis of high pile-column bridge pier, J. Centsouth University. 5(2007)725-729. (In Chinese)

[3] C. J. Zhao, J. Hu, X Xu, Optimum design of large span concrete filled steel tubular arch bridge based on static,stability and modal analysis, J. Journal of Zhejiang University. 2(2005)166-173. (In Chinese)

[4] Q. K, Liu, S. Z. Qiang, Q. Zhang, etal . Structural Analysis of ear-plate cable and beam anchorage For cable-stayed bridge, J. China Journal of Highway and Transport. 15(2002)72-75. (In Chinese) 